\title{
Bioactivity of arid region honey: an in vitro study
}

Serene Hilary ${ }^{1}$, Hosam Habib², Usama Souka', Wissam Ibrahim ${ }^{1}$ and Carine Platat ${ }^{1 *}$

\begin{abstract}
Background: Antioxidant and anti-inflammatory properties of honey have been largely recognized by various studies. Almost all of the potential benefits are associated with polyphenol content. Honey varieties from the arid region are reported to be rich in polyphenols, but data related to its bioactivity in vitro is greatly lacking. This study aimed at establishing the antioxidant and anti-inflammatory properties of arid region honey. Four honey varieties from arid region $(\mathrm{H} 1, \mathrm{H} 2, \mathrm{H} 3$, and $\mathrm{H} 4)$ and two popular non-arid region honey ( $\mathrm{H} 5$ and $\mathrm{H} 6)$ were tested in vitro in this study.

Methods: The erythrocyte membrane protection effect of honey varieties were measured by hemolysis assay after exposing erythrocytes to a peroxide generator. The subsequent production of MDA (malondialdehyde) content in erythrocytes was measured. Immunomodulatory effect of the honey varieties was tested in prostate cancer cells PC3 and PBMC (peripheral blood mononuclear cells) by measuring the IL-6 (interleukin 6) and NO (nitric oxide) levels in cell culture supernatant after incubation with the honey varieties. PC-3 cell viability was assessed after incubation with honey varieties for $24 \mathrm{~h}$.

Results: Arid region honey exhibited superior erythrocyte membrane protection effect with $\mathrm{H} 4$ measuring $1.3 \pm 0$. $042 \mathrm{mMTE} / \mathrm{g}$ and $\mathrm{H} 2$ measuring $1.122 \pm 0.018 \mathrm{mMTE} / \mathrm{g}$. MDA levels were significantly reduced by honey samples, especially H4 (20.819 $\pm 0.63 \mathrm{nmol} / \mathrm{mg}$ protein). We observed a significant decrease in cell population in PC-3 after $24 \mathrm{~h}$ in culture on treatment with honey. A moderate increase in NO levels was observed in both cultures after $24 \mathrm{~h}$ at the same time levels of IL- 6 were remarkably reduced by honey varieties.

Conclusion: The results demonstrate the antioxidant effect of arid region honey due to its erythrocyte membrane protection effect and subsequent lowering of oxidative damage as evident from lower levels of lipid peroxidation byproduct MDA. Arid region honey varieties were as good as non-arid region types at decreasing cell viability of prostate cancer cells. The moderate increase in NO levels in PC-3 and PBMCs were not significant enough to elicit any pro-inflammatory response. However, IL-6 secretion was remarkably reduced by all honey varieties in a comparable level indicating the potential anti-inflammatory property of arid region honey.
\end{abstract}

Keywords: Honey, Arid region, Antioxidant, Anti-inflammation, Anti-tumor, MDA, Hemolysis

\section{Background}

Honey is a viscous liquid produced by bees from the nectar of flowers. It is considered as a wholesome natural food and is also put to medicinal use. Honey has been shown to have broad spectrum anti-microbial activity against gram positive and gram negative bacteria [1] and it is also reported to have wound healing capabilities [2]. Many aspects of honey's healing properties have been identified, including

\footnotetext{
* Correspondence: platatcarine@uaeu.ac.ae

${ }^{1}$ Nutrition and Health Department, College of Food and Agriculture, United

Arab Emirates University, P. O. Box 15551, Al Ain, United Arab Emirates
}

Full list of author information is available at the end of the article antioxidant, anti-inflammatory and anti-tumor properties $[2,3]$. These health properties are of great interest since oxidative stress and inflammation are mechanisms involved in the development of major chronic diseases like cancer [4]. A strong relationship between oxidative stress and inflammation is highly suspected, where the inflammatory process could be activated by a pro-oxidant condition which yet again triggers the release of additional ROS (reactive oxygen species) $[4,5]$. Chronic diseases are increasing throughout the world and a marked increase in chronic disease has been identified in the Arab Gulf Region [6]. 
Oxidative stress is defined as an imbalance between the production of free radicals and reactive metabolites, socalled oxidants or ROS. Protective mechanisms during metabolic reactions involve antioxidants which act mainly as ROS scavengers. The imbalance between oxidative stress and antioxidant scavengers leads to damage of important biomolecules in the cells. Lipids are one biomolecule that represent a significant target for ROS attack. The lipid peroxidation generates other reactive species such as MDA and can increase the risk of mutagenesis. Cancer initiation and progression have been linked to oxidative stress by increasing DNA mutations or inducing DNA damage, genome instability, and cell proliferation [7]. ROS scavenger activity and improvement of the antioxidant status are some of the mechanisms by which honey could exert its antioxidant action [8].

Inflammation is another condition which has been related to the etiology and the development of cancer. Prostate cancer is expected to be one of the major disease in males in the coming decades [6]. There is growing evidence for an implication of chronic inflammation in the origin of many cancers including prostate cancer. Inflammation leads to the release of pro-inflammatory cytokines, particularly IL-6 and NO. They are shown to contribute to the damage of macromolecules and cells, disruption of the cell division process and the transformation of a normal cell to a tumor cell. IL- 6 was clearly identified as a key cytokine implicated in cancers of prostatic tissue, breast tissue, and colorectal tissues [9, 10]. Recently, PBMCs, the active lymphocyte and monocyte fraction of the blood, were shown to be associated with prostate cancer development, through the secretion of pro-inflammatory cytokines most notably IL-6 [11].

A more complex and multifaceted role of IL- 6 and NO related to inflammation has been identified. NO was shown to act as a pro-inflammatory or anti-inflammatory agent, depending upon the site of release and its concentrations [12]. There is growing evidence of an immunomodulatory effect of honey [13-15]. A modulation of IL-6 and NO secretion with honey treatment was observed through in vitro and in vivo studies [8]. Due to its action on the oxidative balance and inflammatory process, honey was shown to modulate the initiation and the progression of many types of cancer among which breast, liver, and colon cancer have been extensively studied $[8,16,17]$. In spite of very promising data, honey's effect on prostate cancer remains to be better explored.

It is now recognized that almost all of the biological activity of honey is credited to its composition [18]. This natural product has a complex chemical composition. All honey types are a mixture of sugars, bee proteins, vitamins, minerals, and polyphenols. Most of the antioxidant benefits of honey are associated with the presence of polyphenols [19]. There is a high correlation between honey's biological activity and the polyphenolic content. Polyphenols are secondary metabolites of plants that act as dietary antioxidants in the body. More than 8000 compounds have been identified hitherto, and some of them like curcumin and catechins are extensively researched for potential therapeutic applications. The common polyphenols reported in honey include gallic acid, catechins, epicatechins, chlorogenic acids, caffeic acids, coumaric acids and quercetin [20]. The content of these polyphenols is different depending on the source and floral origin of honey. The climate where honey is made also significantly influences the polyphenol content and profile. Notably, it was demonstrated that some arid region honey possess a greater amount of polyphenols compared to famous non-arid region honey [21, 22]. Knowing this, it is reasonable to expect from arid region honey greater health benefits. Habib et al. [21] reported that one or more types of honey from arid regions presented a higher antioxidant potential compared to nonarid region honey varieties. Habib et al. [21] compared non arid region honey varieties such as Black Forest and Manuka to arid region honey by using biochemical assays. Non-arid region varieties of honey such as Manuka [23], Gelam [16] and Tualang [24] have been extensively studied in regards to their antioxidant, anti-inflammatory and anti-tumor properties. Results from these studies were promising. However, arid region honey in spite of their high polyphenolic content and greater antioxidant effect, which are both in favor of an anti-tumor effect, remain uninvestigated for their biological activity. Thus further exploration of the health properties of arid region honey is warranted. The aim of this research is to investigate the potential antioxidant, anti-inflammatory, and anti-tumor properties of some of the most popular varieties of arid region honey, and to compare arid region honey to popular non-arid region honey varieties.

\section{Methods \\ Materials}

Histopaque-1077, PBS (phosphate buffered saline), AAPH (2, 2'-azo-bis (2-amidinopropane) dihydrochloride), Trolox, and Trypan blue solution from Sigma-Aldrich; RPMI 1640, FBS (fetal bovine serum), and PenicillinStreptomycin cocktail from Gibco; Bovine Hypothalamus Extract prepared in-house as per the method described by Maciag et al. [25]; Griess Reagent Kit for Nitrite Determination from Molecular Probes; IL-6 ELISA Kit from Novex, Life Technologies.

\section{Honey varieties}

All honey varieties used for the study were purchased from local supermarkets. Honey varieties were selected for in vitro analysis based on the results reported by Habib et al. [21]. Four honey varieties were selected 
from the arid region, two monofloral (H1 and $\mathrm{H} 3)$ and two heterofloral ( $\mathrm{H} 2$ and $\mathrm{H} 4)$, to compare with two nonarid region varieties H5 (monofloral) and H6 (heterofloral). All details about each of these honey types are described in Table 1. For hemolysis and MDA assay, honey varieties were dissolved in PBS to make $10 \%$ solution. For anti-inflammatory studies and cell viability test, $10 \%$ honey solution was prepared by dissolving in serum free media. The honey solutions were centrifuged at $3000 \times \mathrm{g}$ for $10 \mathrm{~min}$ to remove any undissolved particles and filtered using $0.45 \mu \mathrm{m}$ membrane filter.

\section{Hemolysis assay}

Erythrocyte membrane protection effect of the honey varieties was measured using the method described by Banerjee et al. [26] with some modifications. Briefly, whole blood was collected from a healthy donor in EDTA tubes and was centrifuged at $750 \times \mathrm{g}$ for $5 \mathrm{~min}$ at room temperature to separate the platelet rich plasma. The erythrocytes were washed twice with PBS, and a 5\% suspension of the erythrocytes was prepared in PBS for the assay. $500 \mu \mathrm{l}$ of the $5 \%$ erythrocyte suspension was exposed to $200 \mu \mathrm{l}$ of $10 \%$ honey samples (v/v in PBS) or $200 \mu \mathrm{l}$ of Trolox standards for $30 \mathrm{~min}$ at $37^{\circ} \mathrm{C}$. AAPH was added to the samples to attain a concentration of $50 \mathrm{mM}$ in solution, and the tubes were further incubated for further $2 \mathrm{~h}$ at $37^{\circ} \mathrm{C}$. The samples were centrifuged at $3000 \times \mathrm{g}$ for $10 \mathrm{~min}$ and supernatant was collected. The absorbance of the supernatant was measured using a UV-Visible spectrophotometer at wavelength $540 \mathrm{~nm}$. The experiment was carried out in triplicates and data were expressed as mM Trolox Equivalent (TE)/g.

\section{MDA assay}

The decrease of MDA content by honey in erythrocytes after incubation with peroxide generator AAPH was measured by TBARS (Thiobarbituric acid reactive substrates) method described earlier by Seljeskog et al. [27] with some modifications. $500 \mu \mathrm{l}$ of $5 \%$ erythrocyte suspension prepared in PBS was incubated with $200 \mu \mathrm{l}$ of honey varieties $\mathrm{H} 1, \mathrm{H} 2, \mathrm{H} 3, \mathrm{H} 4, \mathrm{H} 5, \mathrm{H} 6(10 \% \mathrm{v} / \mathrm{v}$ in
PBS) or $40 \mathrm{mM}$ Trolox (positive control) or PBS. After 30 min incubation AAPH was added to the samples to attain a concentration of $50 \mathrm{mM}$ in solution and the mixture was incubated for $2 \mathrm{~h}$ at $37^{\circ} \mathrm{C}$. The control used for the experiment was erythrocyte suspension incubated with PBS and treated with AAPH. Following incubation, an equal volume of deionized water was used to lyse the cells. Erythrocyte suspension was directly lysed with deionized water to measure the native MDA content in the cells. The samples were then subjected to protein precipitation using 20\% TCA and centrifuged at high speed to separate the protein. The supernatant was aliquoted to new tubes and were incubated with $0.4 \%$ TBA (Thiobarbituric acid, $w / v$ in $0.2 \mathrm{~N} \mathrm{HCl}$ ) at $60{ }^{\circ} \mathrm{C}$ for one hour for the formation of TBA-MDA adducts. The TBAMDA adduct formed in the sample was measured by Breeze HPLC System (Waters, USA). The mobile phase was methanol:0.05 $\mathrm{M} \mathrm{KH}_{2} \mathrm{PO}_{4}$ buffer $\mathrm{pH} 6.8$ (40:60, v/v) containing $0.2 \%(\mathrm{v} / \mathrm{v})$ triethanolamine. Xterra MS C18 reverse phase column of $5 \mu \mathrm{m}$ pore size was used for the analysis. The column temperature was $35{ }^{\circ} \mathrm{C}$, and the flow rate was $1 \mathrm{ml} / \mathrm{min}$ with an injection volume of $20 \mu \mathrm{l}$. The fluorescence detection wavelength was set at $532 \mathrm{~nm}$ (excitation) and $553 \mathrm{~nm}$ (emission). All samples were analysed in triplicates.

\section{PBMC isolation and culture}

PBMCs were isolated from whole blood using density gradient centrifugation in Histopaque-1077 as per manufacturer's protocol. Briefly, blood samples were obtained from healthy donors in EDTA tubes and diluted with equal volume of PBS and layered over Histopaque and centrifuged at $400 \times \mathrm{g}$ for $30 \mathrm{~min}$ at room temperature in a bench top centrifuge. The layer containing PBMCs were carefully separated from the Histopaque interface and washed twice with serum-free RPMI 1640 medium by centrifuging at $250 \times \mathrm{g}$ for $10 \mathrm{~min}$. The washed PBMCs were resuspended in RPMI 1640 substituted with $10 \% \mathrm{FBS}, 100 \mathrm{u} / \mathrm{ml}$ penicillin, $100 \mu \mathrm{g} / \mathrm{ml}$ streptomycin and $25 \mu \mathrm{g} / \mathrm{ml}$ bovine hypothalamus extract and maintained at $37{ }^{\circ} \mathrm{C}$ in $5 \% \mathrm{CO}_{2}$ incubator.

Table 1 Description of honey varieties by region

\begin{tabular}{|c|c|c|c|c|c|}
\hline Sample & Type & Family & Botanical name & Common name & Country \\
\hline \multicolumn{6}{|c|}{ Arid region } \\
\hline $\mathrm{H} 1$ & Monofloral & Rhamnaccae & Ziziphus spina-csisti & Wild jujube & United Arab Emirates \\
\hline $\mathrm{H} 2$ & Heterofloral & Fabaceae & Acacia tortilis & Wild mountain & Yemen \\
\hline $\mathrm{H} 3$ & Monofloral & Fabaceae & Acacia tortilis & Wild mountain & United Arab Emirates \\
\hline $\mathrm{H} 4$ & Heterofloral & Fabaceae & Acacia tortilis & Mountain herbal & Yemen \\
\hline \multicolumn{6}{|c|}{ Non arid region } \\
\hline $\mathrm{H} 5$ & Monofloral & Myrtaceae & Leptospermum scorparium & Manuka & New Zealand \\
\hline $\mathrm{H} 6$ & Heterofloral & Myrtaceae & Leptospermum scoparium & Black forest & Germany \\
\hline
\end{tabular}




\section{PC-3 culture}

Prostate cancer cell line, PC-3 was purchased from European Collection of Authenticated Cell Cultures (ECACC), UK and was cultured in RPMI 1640 medium substituted with $10 \%$ FBS, $100 \mathrm{U} / \mathrm{ml}$ Penicillin and $100 \mu \mathrm{g} / \mathrm{ml}$ Streptomycin. Upon reaching $80 \%$ confluence, the cells were passaged using $0.25 \%$ Trypsin.

\section{Anti-inflammatory properties}

PC-3 cells and PBMCs were seeded at a density of $4 \times$ $10^{5} \mathrm{cell} / \mathrm{ml}$ in six-well plates, and grown to $80 \%$ confluency in complete growth medium (RPMI 1640 substituted with $10 \% \mathrm{FBS}, 100 \mathrm{u} / \mathrm{ml}$ penicillin, $100 \mu \mathrm{g} / \mathrm{ml}$ streptomycin and $25 \mu \mathrm{g} / \mathrm{ml}$ bovine hypothalamus extract for PBMCs and RPMI 1640 medium substituted with $10 \%$ FBS, $100 \mathrm{U} / \mathrm{ml}$ Penicillin and $100 \mu \mathrm{g} / \mathrm{ml}$ Streptomycin for PC-3). Upon reaching $80 \%$ confluency, the cells were starved overnight with serum-free media and subsequently medium substituted with $10 \%$ honey solution was introduced to cells. The culture was incubated for $24 \mathrm{~h}$ at $37{ }^{\circ} \mathrm{C}$ in $5 \% \mathrm{CO}_{2}$ incubator, following which the culture supernatant was retrieved for the experiments. The IL-6 and NO levels in PC-3 and PBMC culture supernatants were measured by commercial ELISA kit and Griess reaction method respectively. Untreated cells grown in respective complete growth medium served as control for the experiments. All experiments were carried out in triplicates.

\section{Viability test}

Ten percent honey samples were prepared in serum-free media and filter sterilized. PC-3 cells were seeded at a density of $4 \times 10^{5} \mathrm{cell} / \mathrm{ml}$ in six-well plates, upon reaching $80 \%$ confluency, the cells were starved overnight with serum-free media following which medium containing $10 \%$ honey was introduced to cells. The culture was incubated for $24 \mathrm{~h}$ at $37{ }^{\circ} \mathrm{C}$ in $5 \% \mathrm{CO}_{2}$ incubator. Post incubation the viability was assessed by trypan blue exclusion assay, and percentage viability was calculated. Experiments were carried out in triplicates, and untreated cells grown in complete growth medium was used as control.

\section{Statistical analysis}

All data are presented as mean \pm SD. Statistical analysis was done by Post Hoc Tukey Test using SPSS statistical software version 20 for all quantitative parameters to identify the significance of the difference between control and test groups. $P$-value of $<0.05$ was considered as statistically significant.

\section{Results}

Hemolysis assay

Membrane protection effect was used to demonstrate antioxidant activity of the honey varieties. Table 2 shows
Table 2 Anti-hemolytic effect of honey varieties (mM Trolox Equivalent/g)

\begin{tabular}{lc}
\hline Samlple & $m$ Trolox Equivalent/g \\
\hline H1 & $1.046 \pm 0.089^{a}$ \\
H2 & $1.122 \pm 0.018^{b}$ \\
H3 & $1.014 \pm 0.044^{c}$ \\
H4 & $1.30 \pm 0.042^{d}$ \\
H5 & $0.907 \pm 0.053$ \\
H6 & $0.668 \pm 0.040^{e}$ \\
\hline
\end{tabular}

Means \pm s.e. are presented

${ }^{a}$ Significant difference between $\mathrm{H} 1$ and $\mathrm{H} 4$

b Significant difference between $\mathrm{H} 2$ and $\mathrm{H} 5$

'Significant difference between $\mathrm{H} 3$ and $\mathrm{H} 4$

${ }^{d}$ Significant difference between $\mathrm{H} 4$ and $\mathrm{H} 5$

eSignificantly lower than all honey varieties

the results from the hemolysis assay. In this assay, peroxide generator AAPH was added to cells to induce lysis and decrease in hemolysis by honey treatment was measured in terms of trolox equivalents. All honey varieties were found to be effective in protecting the erythrocyte membrane from oxidative damage. In this study, H4 showed the highest antioxidant activity at $1.3 \pm$ $0.042 \mathrm{mMTE} / \mathrm{g}$. This is significantly higher than all other samples except H2. Sample H2 was second in effectively preventing hemolysis indicating a higher antioxidant effect at $1.122 \pm 0.018 \mathrm{mMTE} / \mathrm{g}$. Interestingly, the antioxidant potential of both $\mathrm{H} 2$ and $\mathrm{H} 4$ was significantly higher than both non-arid region types $\mathrm{H} 5$ and $\mathrm{H} 6$, measuring $0.907 \pm 0.053 \mathrm{mMTE} / \mathrm{g}$ and $0.668 \pm 0.040 \mathrm{mMTE} / \mathrm{g}$ respectively. The lowest measured antioxidant effect which stood at $0.668 \pm$ $0.040 \mathrm{mMTE} / \mathrm{g}$ was observed in H6. In comparison H1 and $\mathrm{H} 3$ showed significantly higher erythrocyte membrane protection effect than H6, with $1.046 \pm$ $0.089 \mathrm{mMTE} / \mathrm{g}$ and $1.014 \pm 0.044 \mathrm{mMTE} / \mathrm{g}$, respectively.

\section{MDA assay}

All honey varieties significantly reduced the amount of MDA content formed as a result of peroxyl radicals generated by AAPH (Fig. 1) when compared to the control group (AAPH in Fig. 1). The positive control of the experiment, Trolox, in combination with AAPH, showed a significant lowering of MDA levels with $13.23 \pm$ $1.12 \mathrm{nmol} / \mathrm{mg}$ protein. This was significantly lower than the control and all honey varieties. Arid region honey $\mathrm{H} 4$ demonstrated the overall best antioxidant effect with a measured MDA level of $20.819 \pm 0.63 \mathrm{nmol} / \mathrm{mg}$ protein which indicates its ability to lower oxidative damages than both non-arid region varieties H5 (25.11 \pm $0.42 \mathrm{nmol} / \mathrm{mg}$ protein) and $\mathrm{H} 6(25.98 \pm 0.44 \mathrm{nmol} / \mathrm{mg}$ protein). All other honey varieties presented a comparable effect in reducing oxidative damage to erythrocytes. 


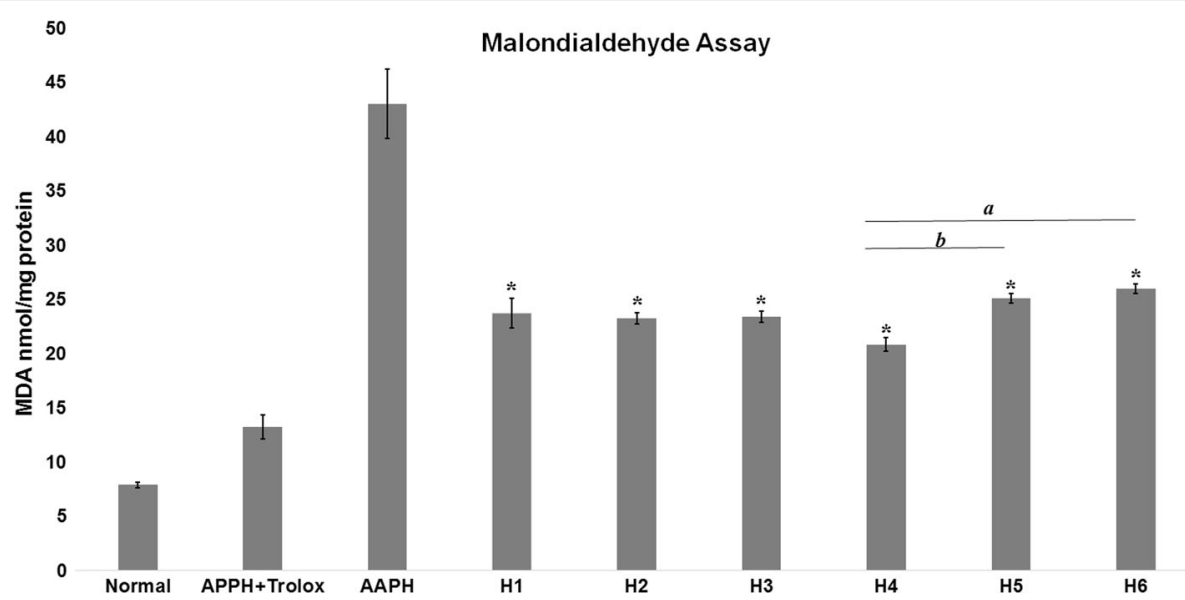

Fig. 1 Malondialdehyde content measured by TBARS assay in erythrocytes after treatment. Data expressed as nmol MDA/mg protein. Normal represented the amount of MDA in erythrocytes without treatment. Normal and AAPH + Trolox were used as positive controls for the experiment. Comparisons using Post Hoc Tukey test was carried out for AAPH, H1, H2, H3, H4, H5, and H6. *Significant decrease in MDA levels compared to AAPH treated group. $a$ - Significant difference in MDA levels between $\mathrm{H} 4$ and $\mathrm{H} 6$. $b$ - Significant difference between $\mathrm{H} 5$ and $\mathrm{H} 6$

\section{Nitric oxide levels}

Nitric oxide level in both PBMC and PC-3 cultures are presented in Fig. 2. The levels detected in PBMCs were significantly higher in all honey varieties except $\mathrm{H} 1$ and $\mathrm{H} 3$ in which percentage detected was similar to control group. Among the arid region honey, the percentage of $\mathrm{NO}$ in $\mathrm{H} 2$ was the highest at $242.03 \% \pm 9.97 \%$. The level of $\mathrm{NO}$ in $\mathrm{H} 4$ treated group in PBMCs was also increased at $160.09 \% \pm 3.58 \%$. Interestingly, both $\mathrm{H} 2$ and $\mathrm{H} 4$ are heterofloral varieties. PBMCs elicited the highest response in $\mathrm{H} 6$ group, which was significantly higher than all other groups, in which the measured percentage of NO level was $289.70 \% \pm 19.99 \%$. Only H2 in the arid region had a comparable effect in PBMCs as seen in H6. The effect of H5 on PBMCs measuring 177.17\% $\pm 5.64 \%$ was only slightly higher than $\mathrm{H} 4$. However, $\mathrm{NO}$ levels in $\mathrm{H} 1$ and $\mathrm{H} 3$ was much lower than H5. PC-3 culture showed the remarkable result in NO production in treatment with the honey samples. The effect of each honey type in the PC-3 cell was different from that of PBMCs. Here, all groups except $\mathrm{H} 3$ and $\mathrm{H} 6$ gave a significantly higher increase in NO production when compared to control. Unlike the response in PBMCs, $\mathrm{H} 1$ recorded the highest percentage increase in $\mathrm{NO}$ at $318.16 \% \pm 7.38 \%$ and $\mathrm{H} 6$ recorded the least increase at $117.94 \% \pm 17.32 \%$. The level of NO increase seen in $\mathrm{H} 1$ groups was similar to $\mathrm{H} 5$ which stood at $311.47 \% \pm 19.38 \%$. This is clear indication that arid region honey $\mathrm{H} 1$ has a comparable effect to that of non-arid region honey $\mathrm{H} 5$. The effect of $\mathrm{H} 2(216.39 \% \pm 17.71 \%)$ and $\mathrm{H} 4 \quad 239.89 \% \pm 47.14 \%)$ was

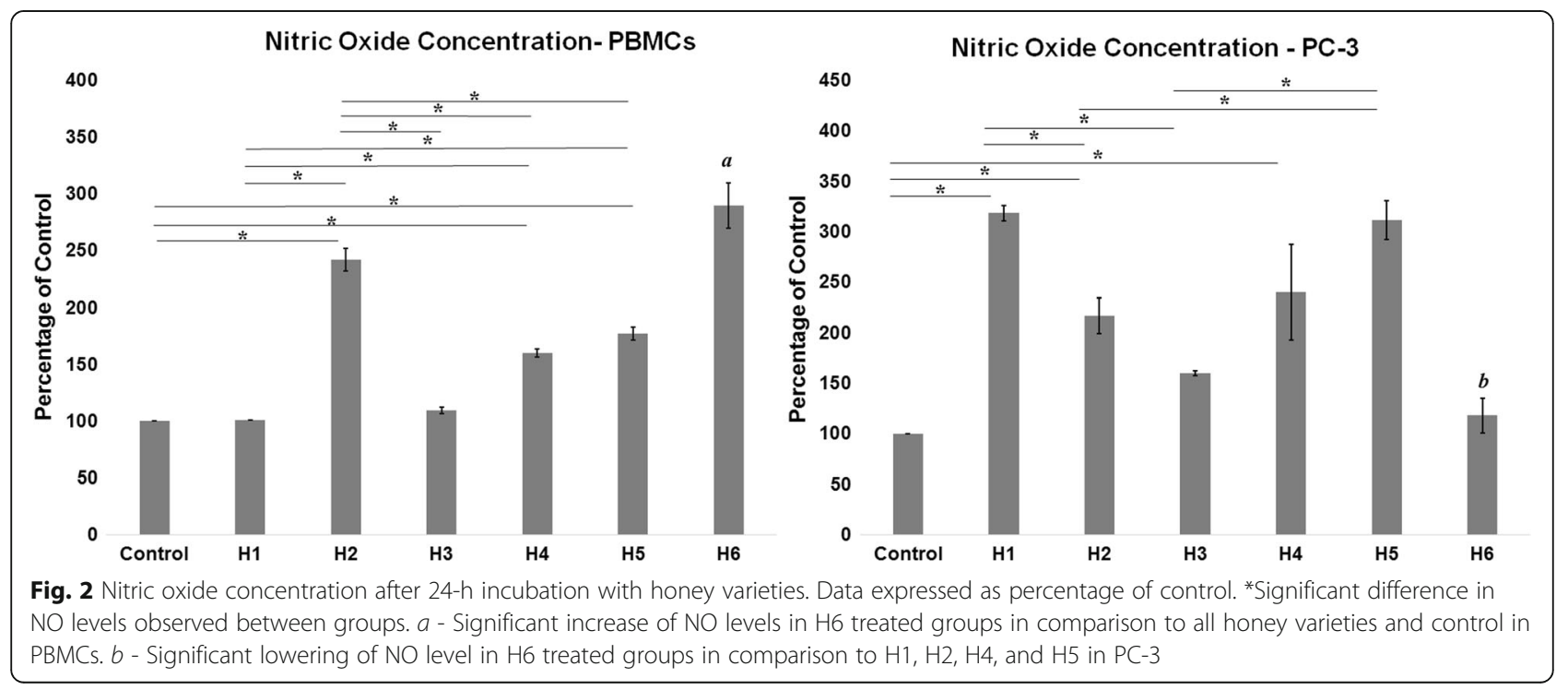


however significantly better than that of $\mathrm{H} 6$ non-arid honey. The response from $\mathrm{H} 3(159.55 \% \pm 2.3 \%)$ measured was higher than control and $\mathrm{H} 6$ although it was not significant.

\section{IL-6 ELISA}

IL-6 secretion by PBMCs and PC-3 cells were lowered when compared to control on treatment with the honey (Fig. 3). The percentage of IL-6 secretion in PBMCs, however, was significantly lowered only in $\mathrm{H} 1(74.56 \% \pm 5.25 \%)$, $\mathrm{H} 3(83.57 \% \pm 4 \%)$ and $\mathrm{H} 6(77.87 \% \pm 0.66 \%)$. Arid region honey $\mathrm{H} 1$ elicited the most effective reduction in PBMCs, and the measured percentage was comparable with nonarid region variety. Meanwhile, H5 $(97.49 \% \pm 2.93 \%)$ gave the least effect in the study. The response induced by $\mathrm{H} 2$ $(93.23 \% \pm 2.8 \%)$ and $\mathrm{H} 4(89.92 \% \pm 5.4 \%)$ from the arid region markedly better than $\mathrm{H} 5$, however, were not significant. From arid region honey, the monofloral varieties (H1 and $\mathrm{H} 3$ ) elicited great reduction when compared to a similar variety from the non-arid region $(\mathrm{H} 5)$. The percentage secretion of IL- 6 by PC-3 cells was considerably lowered in comparison to control. In all groups, the data was significantly lower than the control. All honey varieties showed a similar effect in lowering the IL-6 secretion from PC-3, there were not significantly different from each other.

\section{Cell viability}

After 24-h incubation with honey varieties, there was a marked difference in the morphology of the PC-3 cells treated with honey compared to that of the control (Fig. 4a-g). The honey-treated group appeared to be more rounded and shrunk in size compared to the untreated group which appeared elongated and stretched which is characteristic to PC-3 cells. The viability of the cells in the honey treated group was found to be significantly lower compared to the control (Fig. 4h). The viability of PC-3 cells was effectively reduced by all arid region varieties. $\mathrm{H} 1$ was the most effective honey variety in lowering viability to $66.89 \% \pm 2.76 \%$ which was significantly better than $\mathrm{H} 3$ which has the least capacity in lowering viability measuring $76.08 \% \pm 4.4 \%$.

\section{Discussion}

This in vitro study investigated the antioxidant, antiinflammatory and anti-tumor properties of the popular honey varieties from the arid region. For the study, two monofloral ( $\mathrm{H} 1$ and $\mathrm{H} 3)$ and two heterofloral $(\mathrm{H} 2$ and $\mathrm{H} 4)$ varieties of honey were selected from arid region to compare with popular monofloral and heterofloral varieties from the non-arid region, namely Manuka and Black Forest (H5 and H6, respectively). Globally, antioxidant, anti-inflammatory and anti-tumor effects were demonstrated for arid region honey. Arid region honey showed a greater antioxidant effect than non-arid honey as shown by the prevention of oxidative damages to erythrocytes. The variety $\mathrm{H} 4$, a heterofloral mountain herbal variety from Yemen, was the most effective in lowering erythrocyte lysis by peroxide radicals whereas all other arid region varieties showed comparable effect to non-arid region varieties. Reduction of lipid peroxidation as seen by lowering of MDA levels by $\mathrm{H} 4$ also indicates its superior ability is lowering oxidative damage. Decrease in IL-6 level was observed, in a similar way, in arid and non-arid region honey indicating comparable anti-inflammatory effect of the varieties. One of the most significant results noted was the reduced viability of PC-3 cells on treatment with the honey varieties, indicating its potential anti-tumor effect.

The free radical-induced erythrocytes hemolysis is recognized as a particularly efficient method for evaluation of antioxidant capacity, with some advantages compared

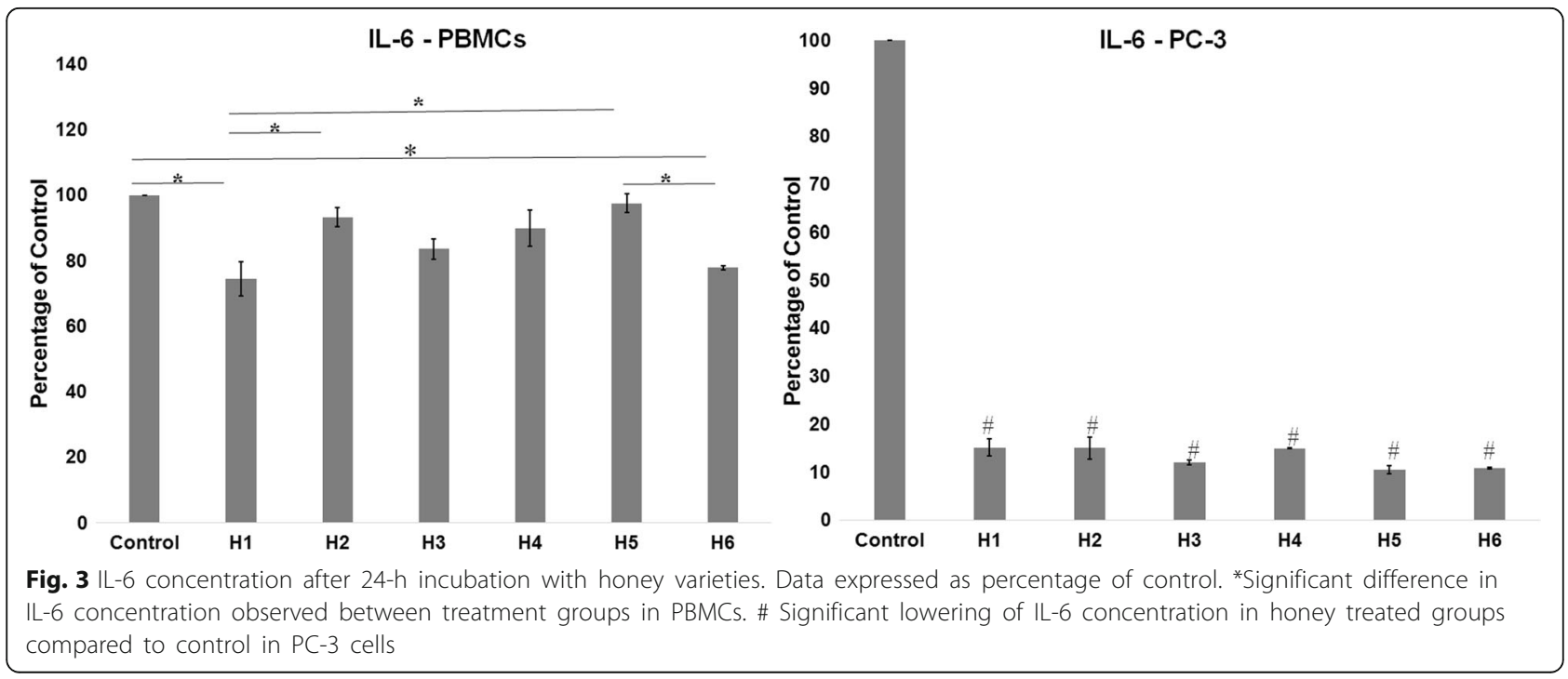



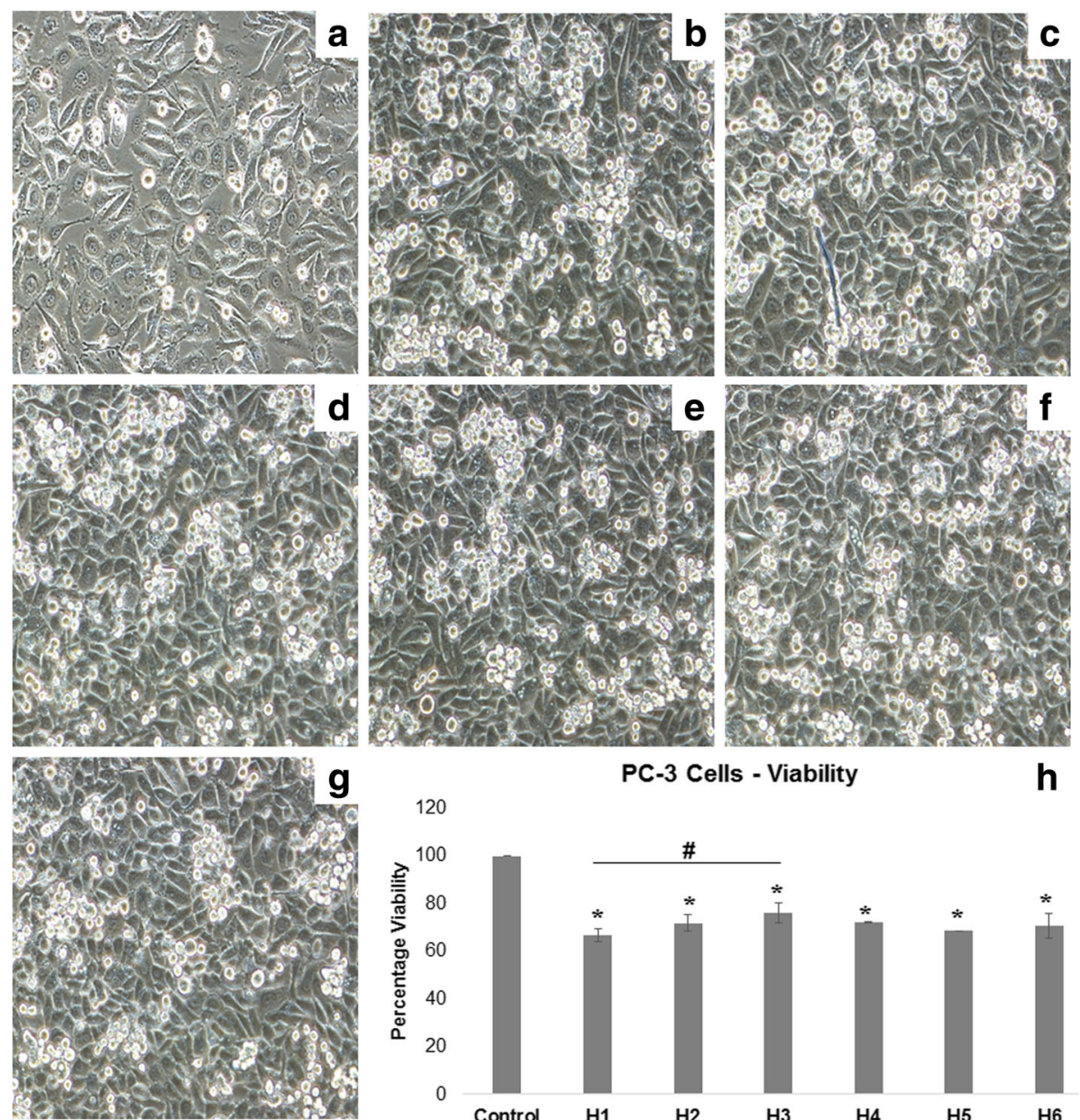

PC-3 Cells - Viability

h

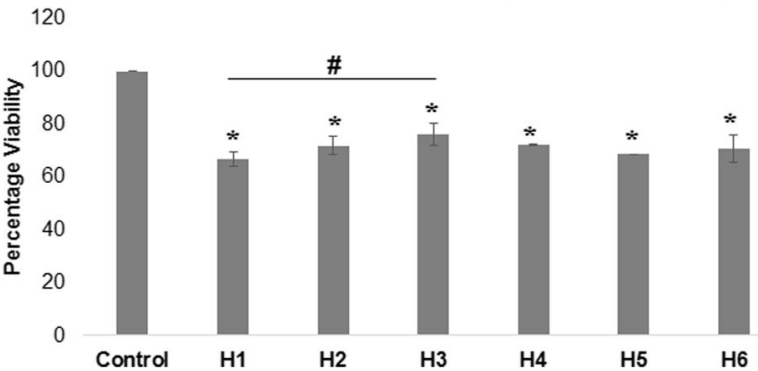

Fig. 4 Viability of PC-3 cells after 24-h incubation with honey. a Untreated Control, b H1, c H2, d H3, e H4, f H5, g H6. Cell under 20X magnification. $\mathbf{h}$ Percentage decrease in viability of cells after $24-\mathrm{h}$ incubation with honey varieties. ${ }^{*}$ Treatment groups shows significant lowering of viability compared to control. \# - Significant difference between $\mathrm{H} 1$ and $\mathrm{H} 3$

to common biochemical assays like TAC or DPPH. It uses free radicals as pro-oxidants and erythrocytes as oxidizable targets so that the results obtained reflect biologically relevant radical-scavenging activity. Lysis of erythrocytes, which transport oxygen and are one of the most abundant cells in the human body, is related to oxidative stress. Free Radicals, generated by this oxidative stress, are known to attack highly unsaturated fatty acids to induce lipid peroxidation, leading to changes in the fluidity of the cell membrane and ultimately to cell injury and lysis. Erythrocytes are more likely to be exposed to this type of oxidative damage due to high lipid content in their membranes and presence of transition metals like iron and copper. Arid region honey demonstrated a protection effect to erythrocytes against lysis by free radicals generated by AAPH. Similar results were observed in an in vivo study where enhanced cytoprotective function was demonstrated against doxorubicin toxicity in mice supplemented with Seder mountain honey [28].
Also, arid region honey was able to protect against lipid peroxidation in erythrocytes. Erythrocytes hemolysis is related to oxidative damages on lipid bilayer. One of the principle markers of oxidative damage in erythrocyte is the lipid peroxidation product MDA. An increase in MDA level will be observed in cells that are exposed to free radicals. Therefore, an effective lowering of MDA levels by honey varieties supports its antioxidant property. While such an antioxidant effect had already been shown by Habib et al. [21], in arid region honey, it was done by using common biochemical assays (DPPH, FRAP, TAC) and not cell-based tests.

The anti-inflammatory effect of honey was long established through various studies $[14,16,23,29]$ on non-arid region honey, yet nothing was available on arid region varieties. The research results demonstrated here indicate that arid region honey also possesses anti-inflammatory effects similar to previously studied non-arid honey types. This is demostrated by its capacity to lower IL- 6 in 
prostate cancer cell line and PBMCs. IL-6, as an early signal, is a key component in the inflammatory process. It is secreted by $\mathrm{T}$ cells and macrophages to stimulate inflammation at the time of infection or tissue damage. It is noteworthy that all honey types were equal in their ability to lower the cytokine level in both cell types. In PBMCs, the decrease in IL-6 levels, however, was not as remarkable as PC-3. This can be related to the fact that prostatic cancer tissue secretes cytokine IL-6 in great quantities and that PBMCs were under normal conditions. As reported earlier expression of IL- 6 is associated with the development of prostate cancer through an immunomodulatory dialog with cancer cells [11]. The result observed in this study takes precedence as it clearly demonstrates an immunomodulatory effect in prostate cancer cell line. Considering that health properties of honey were related to their polyphenol content, the result of this study are in accordance with the recent study in which treatment with polyphenols were able to lower the expression of proinflmmatory cytokines in PBMCs [30].

Surprisingly, where an anti-inflammatory effect of honey could be suggested based on the data of IL-6, the effect of honey on NO production was apparently in favor of a proinflammatory action. Indeed, it was found that all honey varieties were capable of increasing the $\mathrm{NO}$ levels in varying degrees in PC-3 cells and PBMC, which accounts for initiation of systemic pro-inflammatory response. $\mathrm{NO}$, which is an important mediator of inflammation, is a double-edged compound, playing a paradoxical role depending upon the concentration at which it is secreted by cells. Typically, under low physiological concentration, $\mathrm{NO}$ acts as an antiinflammatory molecule, but at higher concentration it acts as a mediator of inflammation [12]. Here, the increase of $\mathrm{NO}$ production was least in both cultures on treatment with arid region variety $\mathrm{H} 3$. On the contrary, the non-arid region types gave varying data in both cultures, where $\mathrm{H} 6$ gave a significant increase of $\mathrm{NO}$ in PBMCs while the increase was minimal in PC-3 cells. However in both cell types studied, an increase of NO by a $0.6-2 \mu \mathrm{M}$ from the control concentration was observed, this cannot be significant enough to be considered pro-inflammatory as it is reported that a 100 fold increase is at least observed at the time of pro-inflammatory signaling by $\mathrm{NO}[31,32]$. Therefore, it seems that the increase of NO levels which was detected in our study was not strong enough to elicit any proinflammatory response.

Finally, since oxidative stress and inflammation are two major mechanisms involved in the etiology and development of cancer [4], the research results identified here indicate that arid region honey could effectively regulate growth and metastasis of prostate cancer cells. This is supported by our result which have shown that IL-6 was reduced with supplementation of honey in PC3 cells. IL-6 is associated with aggressive prostate cancer phenotype and may be involved in the metastatic process through regulation of epithelial-mesenchymal transition and homing of cancer cells to the bone [9]. It is also interesting to note that in vivo studies in animals and human clinical trials have been conducted with antiIL-6 monoclonal antibodies to target prostate tumor [33]. This would mean that any factor able to reduce the secretion of IL-6 could exert an anti-tumor action. In addition, we found the viability of $\mathrm{PC}-3$ cells was reduced on treatment with honey for $24 \mathrm{~h}$. The capacity of honey observed in this study, (both arid and non-arid region varieties) to significantly reduce the population of PC-3 cells and reduce its capacity to secrete IL-6, enables us to suggest a possible anti-tumor effect for honey in prostate cancer.

A tight inter-relationship between oxidative stress and inflammation is now well acknowledged [34]. However, the sequence of these events remains unclear and impedes the identification of therapeutic targets. Some studies clearly showed that one of the important aspects of inflammation is the sudden increase in the superoxides, also called oxidative burst, as a result of phagocyte activation. Also, it was observed that heme released by erythrocytes as a result of lysis lead to neutrophil migration and triggered oxidative burst by these cells [35]. The capacity of antioxidants to protect the integrity of the cell membrane was found to be a very critical event in preventing inflammation, indicating that oxidative damages would be the one to induce the inflammatory process. The present study suggest that honey increased protection of erythrocytes against lysis through the reduction of lipid peroxidation. This supports the theory of the antioxidant effect in honey.

Globally, our results are significant in the context that accumulation of oxidative damages in the body can later result in the development of most chronic diseases. The erythrocyte membrane protective function of honey can effectively reduce the risk of inflammation from hemolysis which has been implicated in several diseases leading to organ damage. For example, the cytoprotective effect of Seder honey variety, from the arid region, was assessed in doxorubicin-treated mice [28]. In this study, enhanced liver function and improvement in symptoms such as bleeding were demonstrated in the treated groups.

In view of the fact that polyphenols in honey are reported to have antioxidant and anti-inflammatory effects [36-38], it can be reasonably assumed that similar results would occur using the honey varieties from arid region which have high polyphenol content. A more comprehensive study on the polyphenol content of these varieties would demonstrate which molecules are directly involved in bringing about this effect. An earlier study by Habib et al. [21] had probed more than ten arid region varieties against non-arid region types showing 
the polyphenol content in the honey were comparable and in some varieties even better than non-arid region varieties. Greater health effects of arid region honey would be expected if a higher polyphenol content is present. Here, under in vitro conditions, the antioxidant potential of arid region honey was either comparable or stronger, in case of $\mathrm{H} 4$, than non-arid region varieties. The anti-inflammatory and anti-tumor properties of the arid region were found to be comparable to non-arid region types.

This work is presenting some limitations. One limitation was related to the concentration of honey and the time of cell exposure to honey. This could be addressed by probing the different concentrations of honey varieties used in this study (concentration of honey used in our study was $10 \%$ which was calculated based on results reported from the study by Habib et al.) and by assessing the long-term effect of honey supplementation in cell culture. Further experiments should be performed to clarify the antiinflammatory role of arid region honey, including the study of additional cytokines like TNF-alpha, in PBMCs after inducing inflammation.

\section{Conclusions}

Results obtained from our study has demonstrated that arid region honey is a potential antioxidant, anti-inflammatory and anti-tumor agent, as shown by the study of erythrocyte lysis, erythrocyte membrane protection against oxidative damages, cancer cell growth inhibition, and reduction of pro-inflammatory marker secretion in PC-3 and PBMC culture. Compared to non-arid region varieties, arid region honey showed a greater antioxidant potential and comparable anti-inflammatory and anti-tumor effect. An immunomodulatory effect of arid region and non-arid region honey was further suggested. All of this is in favor of a promising use of arid region honey as a therapeutic product for major chronic diseases, especially cancer.

\section{Abbreviations \\ AAPH: 2, 2'-azo-bis (2-amidinopropane) dihydrochloride; FBS: Fetal bovine serum; IL-6: Interleukin-6; MDA: Malondialdehyde; NO: Nitric oxide; PBMC: Peripheral blood mononuclear cells; PBS: Phosphate buffered saline; ROS: Reactive oxygen species; TBA: Thiobarbituric acid; TBARS: Thiobarbituric acid reactive substance}

\section{Acknowledgments}

The authors would like to thank United Arab Emirates University for fully funding the project through UPAR grant (31 F046-UPAR(5)2013). We thank Ms. Traci Jackson of Nutrition and Health Department, United Arab Emirates University for her comments and suggestions that greatly improved the manuscript.

\section{Funding}

This study was financially supported by the United Arab Emirates University Program for Advanced Research in the year 2013, grant number 31 F046UPAR(5)2013. The funding agent had no role in the study design, analysis, decision to publish or preparation of the manuscript.

\section{Availability of data and materials}

The data sets analyzed during the current study available from the corresponding author on reasonable request.

\section{Authors' contributions}

$\mathrm{SH}$ performed the assays in the laboratory in collaboration with the laboratory technician. She conducted the statistical analysis and wrote the draft manuscript. $\mathrm{HH}$ was involved in the protocol development and some laboratory assessments. US helped in the laboratory assessment. WI provided significant recommendations for the design and the assays. CP was the principal investigator of the study. She developed the protocol, obtained the funding. She assisted the first author in analyzing, writing and finalizing the manuscript. All authors read and approved the final manuscript.

\section{Competing interests}

The authors declare that they have no competing interests.

\section{Consent for publication}

Not applicable

\section{Ethics approval and consent to participate}

This study uses a single sample of human blood for the purpose of isolating erythrocytes for hemolysis assay and PBMCs for anti-inflammation studies, both induced by honey. The objective here was not to observe the health condition of the donor or assess any biochemical parameters in the blood itself. All conclusions reported in this study are pertaining to the characteristics of the honey and it is independent of any information regarding the donor's health status. The blood sample used for the purpose came from the principle investigator. No ethical approval was required from United Arab Emirates University's Institutional Review Board under this circumstance. The PI of the study, who already had all information about the purpose of the blood collection and its end use volunteered to donate blood sample for the study. Blood collection was carried out by a trained physician in a hospital after signing informed consent.

\section{Publisher's Note}

Springer Nature remains neutral with regard to jurisdictional claims in published maps and institutional affiliations.

\section{Author details}

${ }^{1}$ Nutrition and Health Department, College of Food and Agriculture, United Arab Emirates University, P. O. Box 15551, Al Ain, United Arab Emirates.

${ }^{2}$ Alexandria University, 22 El-Guish Road, El-Shatby, Alexandria 21526, Egypt.

Received: 1 November 2016 Accepted: 7 March 2017

Published online: 29 March 2017

\section{References}

1. Mohapatra DP, Thakur V, Brar SK. Antibacterial efficacy of raw and processed honey. Biotechnol Res Int. 2011;2011:917505.

2. Hadagali MD, Chua LS. The anti-inflammatory and wound healing properties of honey. Eur Food Res Technol. 2014;239(6):1003-14.

3. Gorjanović SŽ, Alvarez-Suarez JM, Novaković MM, Pastor FT, Pezo L, Battino M, Sužnjević DŽ. Comparative analysis of antioxidant activity of honey of different floral sources using recently developed polarographic and various spectrophotometric assays. J Food Compos Anal. 2013;30(1):13-8.

4. Reuter S, Gupta SC, Chaturvedi MM, Aggarwal BB. Oxidative stress, inflammation, and cancer: how are they linked? Free RadicBiol Med. 2010; 49(11):1603-16.

5. Valko M, Izakovic M, Mazur M, Rhodes C, Telser J. Role of oxygen radicals in DNA damage and cancer incidence. Mol Cell Biochem. 2004;266(1-2):37-56.

6. Al-Othman S, Haoudi A, Alhomoud S, Alkhenizan A, Khoja T, Al-Zahrani A. Tackling cancer control in the Gulf Cooperation Council Countries. Lancet Oncol. 2015;16(5):e246-57.

7. Visconti R, Grieco D. New insights on oxidative stress in cancer. Curr Opin Drug Discov Devel. 2009;12(2):240-5.

8. Erejuwa OO, Sulaiman SA, Wahab MSA. Effects of honey and its mechanisms of action on the development and progression of cancer. Molecules. 2014;19(2):2497-522.

9. Klink JC, Bañez LL, Gerber L, Lark A, Vollmer RT, Freedland SJ. Intratumoral inflammation is associated with more aggressive prostate cancer. World J Urol. 2013;31(6):1497-503.

10. De Simone V, Franzè E, Ronchetti G, Colantoni A, Fantini MC, Di Fusco D, Sica GS, Sileri P, MacDonald TT, Pallone F et al. Th17-type cytokines, IL-6 and 
TNF-a synergistically activate STAT3 and NF-kB to promote colorectal cancer cell growth. Oncogene. 2015;34(27):3493-503.

11. Salman $H$, Ori $Y$, Bergman $M$, Djaldetti $M$, Bessler $H$. Human prostate cancer cells induce inflammatory cytokine secretion by peripheral blood mononuclear cells. Biomed Pharmacother. 2012;66(5):330-3.

12. Sharma JN, Al-Omran A, Parvathy SS. Role of nitric oxide in inflammatory diseases. Inflammopharmacology. 2007;15(6):252-9.

13. Majtan J. Honey: an immunomodulator in wound healing. Wound Repair Regen. 2014;22(2):187-92.

14. Kassim M, Achoui M, Mansor M, Yusoff KM. The inhibitory effects of Gelam honey and its extracts on nitric oxide and prostaglandin E 2 in inflammatory tissues. Fitoterapia. 2010;81(8):1196-201.

15. Tonks A, Cooper RA, Price AJ, Molan PC, Jones KP. Stimulation of TNF-a release in monocytes by honey. Cytokine. 2001;14(4):240-2.

16. Wen CTP, Hussein SZ, Abdullah S, Karim NA, Makpol S, Yusof YAM. Gelam and nenas honeys inhibit proliferation of HT 29 colon cancer cells by inducing DNA damage and apoptosis while suppressing inflammation. Asian Pac J Cancer Prev. 2012;13(4):1605-10

17. Nik Muhd Khuzaimi Nik M, Hassan R, Ang CY, Abdullah AD, Muhammad Amiro Rasheeq Mohd R, Sulaiman SA. Antileukemic effect of Tualang Honey on acute and chronic leukemia cell lines. Biomed Res Int. 2015; 2015:7. 307094.

18. El Sohaimy S, Masry S, Shehata M. Physicochemical characteristics of honey from different origins. Ann Agric Sci. 2015;60(2):279-87.

19. Chua LS, Rahaman NLA, Adnan NA, Eddie Tan TT. Antioxidant activity of three honey samples in relation with their biochemical components. J Anal Methods Chem. 2013;2013:8.

20. Zhang X-H, Wu H-L, Wang J-Y, Tu D-Z, Kang C, Zhao J, Chen Y, Miu X-X, Yu $R-Q$. Fast HPLC-DAD quantification of nine polyphenols in honey by using second-order calibration method based on trilinear decomposition algorithm. Food Chem. 2013;138(1):62-9.

21. Habib HM, Al Meqbali FT, Kamal H, Souka UD, Ibrahim WH. Bioactive components, antioxidant and DNA damage inhibitory activities of honeys from arid regions. Food Chem. 2014;153:28.

22. Habib HM, Al Meqbali FT, Kamal H, Souka UD, Ibrahim WH. Physicochemical and biochemical properties of honeys from arid regions. Food Chem. 2014;153:35.

23. Almasaudi SB, El-Shitany NA, Abbas AT, Abdel-Dayem UA, Ali SS, Al Jaouni SK, Harakeh S. Antioxidant, anti-inflammatory, and antiulcer potential of manuka honey against gastric ulcer in rats. Oxid Med Cell Longev. 2016; 2016:3643824

24. Ghashm AA, Othman NH, Khattak MN, Ismail NM, Saini R. Antiproliferative effect of Tualang honey on oral squamous cell carcinoma and osteosarcoma cell lines. BMC Complement Altern Med. 2010;10:49.

25. Maciag T, Cerundolo J, Ilsley S, Kelley PR, Forand R. An endothelial cell growth factor from bovine hypothalamus: identification and partial characterization. Proc Natl Acad Sci U S A. 1979;76(11):5674-8.

26. Banerjee A, Kunwar A, Mishra B, Priyadarsini Kl. Concentration dependent antioxidant/pro-oxidant activity of curcumin studies from AAPH induced hemolysis of RBCs. Chem Biol Interact. 2008;174(2):134.

27. Seljeskog E, Hervig T, Mansoor MA. A novel HPLC method for the measurement of thiobarbituric acid reactive substances (TBARS). A comparison with a commercially available kit. Clin Biochem. 2006;39(9):947-54

28. Ganash MA, Mujallid MI, Al-Robai AA, Bazzaz AA. Cytoprotectivity of the natural honey against the toxic effects of Doxorubicin in mice. Adv Biosci Biotechnol. 2014;5(3):252-60.

29. Ahmad I, Jimenez H, Yaacob NS, Yusuf N. Tualang honey protects keratinocytes from ultraviolet radiation-induced inflammation and DNA damage. Photochem Photobiol. 2012;88(5):1198-204.

30. Siard MH, Mcmurry KE, Adams AA. Effects of polyphenols including curcuminoids, resveratrol, quercetin, pterostilbene, and hydroxypterostilbene on lymphocyte pro-inflammatory cytokine production of senior horses in vitro. Vet Immunol Immunopathol. 2016;173:50-9.

31. Guzik T, Korbut R, Adamek-Guzik T. Nitric oxide and superoxide in inflammation. J Physiol Pharmacol. 2003;54:469-87.

32. Haverkamp J, Charbonneau B, Ratliff TL. Prostate inflammation and its potential impact on prostate cancer: a current review. J Cell Biochem. 2008; 103(5):1344-53.

33. Hudes G, Tagawa ST, Whang YE, Qi M, Qin X, Puchalski TA, Reddy M, Cornfeld M, Eisenberger M. A phase 1 study of a chimeric monoclonal antibody against interleukin-6, siltuximab, combined with docetaxel in patients with metastatic castration-resistant prostate cancer. Invest New Drugs. 2013;31(3):669-76.

34. Codoñer-Franch P, Valls-Bellés V, Arilla-Codoñer A, Alonso-Iglesias E. Oxidant mechanisms in childhood obesity: the link between inflammation and oxidative stress. Trans Res J Lab Clin Med. 2011;158(6):369.

35. Graca-Souza AV, Arruda MAB, de Freitas MS, Barja-Fidalgo C, Oliveira PL. Neutrophil activation by heme: implications for inflammatory processes. Blood. 2002;99(11):4160-5.

36. Alvarez-Suarez JM, Tulipani S, Díaz D, Estevez Y, Romandini S, Giampieri F, Damiani E, Astolfi P, Bompadre S, Battino M. Antioxidant and antimicrobial capacity of several monofloral Cuban honeys and their correlation with color, polyphenol content and other chemical compounds. Food Chem Toxicol. 2010;48(8):2490-9.

37. Gheldof N, Wang X-H, Engeseth NJ. Buckwheat honey increases serum antioxidant capacity in humans. J Agric Food Chem. 2003;51(5):1500-5.

38. Blasa M, Candiracci M, Accorsi A, Piacentini MP, Piatti E. Honey flavonoids as protection agents against oxidative damage to human red blood cells. Food Chem. 2007;104(4):1635-40.

\section{Submit your next manuscript to BioMed Central and we will help you at every step:}

- We accept pre-submission inquiries

- Our selector tool helps you to find the most relevant journal

- We provide round the clock customer support

- Convenient online submission

- Thorough peer review

- Inclusion in PubMed and all major indexing services

- Maximum visibility for your research

Submit your manuscript at www.biomedcentral.com/submit
) Biomed Central 